\title{
Proteomic-based identification of HSP70 as a tumor-associated antigen in ovarian cancer
}

\author{
XIN-XIN LIU ${ }^{1,3}$, HUA YE $^{1}$, PENG WANG $^{1}$, LIU-XIA LI $^{1}$, YI ZHANG ${ }^{1}$ and JIAN-YING ZHANG ${ }^{1,2,3}$ \\ ${ }^{1}$ Center for Tumor Biotherapy, The First Affiliated Hospital and College of Public Health, Zhengzhou University; \\ ${ }^{2}$ Henan Academy of Medical and Pharmaceutical Sciences, Zhengzhou University, Zhengzhou, Henan 450052; \\ ${ }^{3}$ Department of Biological Sciences and Border Biomedical Research Center, \\ The University of Texas at El Paso, El Paso, TX 79968, USA
}

Received August 19, 2016; Accepted November 21, 2016

DOI: $10.3892 /$ or.2017.5525

\begin{abstract}
Ovarian cancer commonly presents without prominent symptoms and is consequently diagnosed at advanced stages with unfavorable prognosis. Novel serological biomarkers for the early detection and clinical management of ovarian cancer are imminently needed. Proteomic-based methods for biomarker discovery are promising strategies implemented in cancer research. The aim of the present study was to identify new tumor antigens from the ovarian cancer cell line SKOV3 and their associated autoantibodies in sera of patients with ovarian cancer employing proteomicbased approaches. Proteins from the ovarian cancer cell line SKOV3 were extracted by two-dimensional polyacrylamide gel electrophoresis (2-DE) followed by western blotting and antibody reaction with sera from patients with ovarian cancer and normal controls. Positive spots were excised from Coomassie blue-stained gels and identified by liquid chromatography-tandem mass spectrometry (LC-MS/MS). The $2-\mathrm{DE}$ analysis results revealed a total of 14 protein spots on the gel, and 7 proteins were finally identified by LC-MS/MS. In the subsequent experiment, using immunoassay on ovarian cancer sera and tissue-array slides, the well-known protein HSP70 was selected in order to validate this proteomic-based approach. In conclusion, the proteomic method used in the present study is a powerful instrument for identifying novel serum markers that may exhibit clinical usefulness in cancer.
\end{abstract}

\section{Introduction}

Ovarian cancer is responsible for more than half of the deaths related to gynecological malignancies $(1,2)$. Due to the lack of sensitive tests for the detection of early-stage disease, which

Correspondence to: Dr Jian-Ying Zhang, Center for Tumor Biotherapy, The First Affiliated Hospital and College of Public Health, Zhengzhou University, 1 Jianshe Avenue, Zhengzhou, Henan 450052, P.R. China

E-mail: jianyingzhang@hotmail.com

Key words: proteomics, autoantibody, HSP70, ovarian cancer, LC-MS/MS is frequently asymptomatic, $75 \%$ of malignant ovarian tumors are discovered at a late stage, with a 5-year survival rate of $\sim 30 \%(3,4)$. Although, the majority of patients primarily respond to chemotherapy, the relapse rate is more than $85 \%$. The utilization of serum-soluble tumor antigens, such as CA-125, a biomarker used for the detection of ovarian cancer has been limited due to the insufficient specificity and sensitivity of these antigens, particularly for incipient tumors (5-7). Increased levels of CA-125, the most widely utilized serum biomarker for ovarian cancer, occur in merely $50 \%$ of stage I patients and are also present in healthy women $(5,6)$. Therefore, it is essential to find novel biomarkers for the early diagnosis, prediction of prognosis, monitoring of therapy and to develop new treatment methods, such as immunotherapy, for the management of ovarian cancer $(5,6,8)$.

Proteomic technology has emerged in the last decade as a powerful device used to reveal the molecular mechanisms of the tumor microenvironment and malignant cells in patients with cancer (9). Proteomics has provided effective insight into the disruption of signaling pathways within tumor cells, allowing for the detection of new targets for drug reaction, possible diagnostic markers and prognostic symbols of outcome and response to therapy $(10,11)$. The proteome exhibits all the probable gene products of a cell. Proteins may exist in different forms that vary within a particular cell or in diverse cells, due to modifications derived from translational, post-translational, regulatory and degradable processes that influence protein localization, structure and function. Proteomic methodology characterizes all proteins in a biological system, including complex features, such as isoforms, modifications, functional structures and interactions. Particularly in cancer biomarker discovery, two-dimensional gel electrophoresis, mass spectrometry (MS) and protein microarrays, in combination with advanced bioinformatics, have become useful tools to identify proteins.

In the present study, we employed a proteomic-based approach to identify tumor antigens that produce a humoral immune feedback in patients with ovarian cancer. Proteins from the ovarian cancer cell line SKOV3 were separated by 2-DE, transferred onto nitrocellulose (NC) membranes and subsequently sera from ovarian cancer patients and normal individuals were screened by western blotting for antibodies 
which react against separated proteins. Proteins inducing an immune reaction were isolated, and then identified by MS. Using this technique various tumor antigens were discovered to react more frequently with the sera of ovarian cancer patients compared to normal individuals. These identified biomarkers may be potential candidates for screening and early diagnosis of ovarian cancer.

\section{Materials and methods}

Sera sample collection. In the present study, 120 sera from patients with ovarian cancer and 85 sera from normal controls were obtained from the sera bank in the Cancer Autoimmunity Research Laboratory at the University of Texas, El Paso (UTEP). The sera were first handled by our clinical partners. These ovarian cancer sera were obtained at the initial time of cancer diagnosis, prior to patients being cured with chemotherapy or radiotherapy. Normal control sera were amassed during annual health examinations from adults without apparent evidence of malignancy. Due to regulations regarding studies on human subjects, the identification number and name of the patients were not revealed to investigators, and some clinical information concerning the sera was not available. The present study was approved by the Institutional Review Board of UTEP and collaborating institutions. All procedures performed in the present study were in accordance with the ethical standards of the Institutional Review Board of UTEP.

Cell culture and cell extracts. The ovarian cancer cell line SKOV3 was purchased from the American Type Culture Collection (ATCC; Manassas, VA, USA), and cultured in McCoy's 5A medium (Invitrogen, Carlsbad, CA, USA) supplemented with $10 \%$ fetal bovine serum (FBS), $100 \mathrm{U} / \mathrm{ml}$ penicillin and $100 \mathrm{U} / \mathrm{ml}$ streptomycin. The cells were cultured in $75-\mathrm{cm}^{2}$ Falcon tissue culture flasks and allowed to reach $90 \%$ confluence. Thereafter, the cells were rinsed once with McCoy's 5A medium without FBS and unloaded from the flask by incubating the cells with a solution including trypsin-EDTA (Gibco, Carlsbad, CA, USA), and subsequently harvested in a 15-ml centrifuge tube for further study.

Two-dimensional gel electrophoresis (2-DE) analysis. SKOV3 cells were directly lysed in rehydration sample buffer [8 M urea, $50 \mathrm{nM}$ dithiothreitol (DTT), 4\% 3-[(3-cholamidopropyl) dimethylammonio]-1-propanesulfonate (CHAPS), $0.2 \%$ Bio-Lyte $3 / 10$ ampholyte, and $0.001 \%$ bromophenol blue) as obtained by Bio-Rad Laboratories (Hercules, CA, USA) and were vigorously vortexed for $90 \mathrm{~min}$ at room temperature (RT). Insoluble substances were removed by centrifugation at $13,200 \mathrm{x} \mathrm{rpm}$ for $30 \mathrm{~min}$ at $4^{\circ} \mathrm{C}$. The supernatant was collected and the protein concentration was assessed using the Bradford assay (Bio-Rad Laboratories). For the first dimensional gel electrophoresis analysis, a total of $150 \mu \mathrm{g}$ of protein was mixed with rehydration buffer containing a trace bromophenol blue prepared in proteomic-grade water and applied on a $\mathrm{pH} 3.0-10.0$, 7-cm isoelectric focusing (IEF) strip (Bio-Rad Laboratories). IEF was performed at a current of $50 \mathrm{~mA} / \mathrm{gel}$, $250 \mathrm{~V}$ for $30 \mathrm{~min}$, followed by $4,000 \mathrm{~V}$ for $1.5 \mathrm{~h}$, and an additional $4,000 \mathrm{~V}$ for $5 \mathrm{~h}$. Strips were immediately stored at $-80^{\circ} \mathrm{C}$ for 2-DE analysis. For this analysis, $12 \%$ SDS-polyacrylamide gels (SDS-PAGE) were used. Proteins were subsequently transferred onto NC membranes for western blot analysis or stained with $0.1 \%$ Coomassie blue R-250 prepared in $10 \%$ acetic acid. The spots were visualized using PDQuest 2-DE analysis software as described in the manufacturer's manual (Bio-Rad Laboratories), as well as in our previous study (12).

In-gel digestion. Excised gel pieces were destained with $40 \mathrm{mM} \mathrm{NH} \mathrm{NCO}_{3}$ in $50 \%$ acetonitrile (ACN). Reduction was performed with $5 \mathrm{mM}$ Tris(2-carboxyethyl)phosphine hydrochloride (TCEP) for $1 \mathrm{~h}$ at room temperature followed by alkylation with $50 \mathrm{mM}$ of iodoacetamide (both from Sigma-Aldrich, St. Louis, MO, USA) at room temperature in the dark for $1 \mathrm{~h}$. The dehydrated gel pieces were then digested with trypsin in $10 \mathrm{mM} \mathrm{NH}_{4} \mathrm{HCO}_{3}$ for $18 \mathrm{~h}$ and peptide digests were extracted using extraction buffer $(1: 2 \mathrm{v} / \mathrm{v}$ $5 \%$ formic acid/ACN).

NanoLC-ESI-MS/MS analysis. The digests were analyzed on an Eksigent NanoLC ${ }^{\text {тм }}$-1D-Plus (AB Sciex, Framingham, MA, USA) coupled to a Thermo Fisher LTQ XL ${ }^{\mathrm{TM}}$ Linear Ion Trap Mass Spectrometer (LTQ XL-MS) as follows: the digests were loaded onto an online dual trap set-up (Eksigent Chrom XP NanoLC Trap-Column C18-CL-3 $\mu \mathrm{m} 120 \AA$ A, $350 \mu \mathrm{m}$ x 0.5 mm) at a flow rate of $1.5 \mu \mathrm{l} / \mathrm{min}$ using channel $1 \mathrm{~A}$ solution $(98 \%$ water, $2 \% \mathrm{ACN}, 0.5 \%$ formic acid). Separation was achieved on an Eksigent Chrom XP NanoLC C18-reverse phase column (3C18-CL-3 $\mu \mathrm{m} 120 \AA$, $0.075 \times 150 \mathrm{~mm}$ ) using 2 channel mobile phases (solvent $2 \mathrm{~A}, 5 \% \mathrm{ACN} / 0.1 \% \mathrm{FA}$; solvent $2 \mathrm{~B}$, $80 \% \mathrm{ACN} / 0.1 \% \mathrm{FA}$, on a linear gradient of $5-45 \%$ 2B solvent over $60 \mathrm{~min}$ at a flow rate of $300 \mathrm{nl} / \mathrm{min})$. The MS system was set to perform one full scan (400-1,700 m/z range) followed by MS/MS scans of the 10 most abundant parent-ions (ESI voltage, $3 \mathrm{kV}$; isolation width, $3.0 \mathrm{~m} / \mathrm{z} ; 35$ normalized collision energy). The dynamic exclusion was set to collect each parent-ion twice and then excluded for $120 \mathrm{sec}$.

Data analysis. The resulting MS/MS spectra (350-5,000 Da, monoisotopic) were searched against a UniProt protein database downloaded on April 04, 2013 comprised of Homo sapiens, Bos Taurus and porcine trypsin using a SEQUEST ${ }^{\circledR}$ algorithm in Proteome Discoverer 1.4 software (Thermo Scientific, San Jose, CA, USA). The parameters for database search were: i) 2.0 and $1.0 \mathrm{Da}$ for peptide and fragment mass tolerance respectively; ii) full digest using trypsin after K/R with up to two missed cleavages allowed; and iii) methionine (M) oxidation as a fixed modification, and cysteine (C) carbamidomethylation, and deamidation of asparagine $(\mathrm{N})$, and glutamine (Q) as variable modifications. At least two peptides were used for assignment of proteins and search results were filtered for a false discovery rate (FDR) of $1 \%$ employing a decoy search strategy utilizing a reverse database.

Enzyme-linked immunosorbent assay (ELISA). The HSP70 protein was purchased from Abcam (Cambridge, MA, USA). This protein was diluted in phosphate-buffered saline (PBS) with a final concentration of $1 \mu \mathrm{g} / \mathrm{ml}$ for coating polystyrene 96-well microtiter plates (Thermo Scientific, Waltham, MA, USA). Plates were then blocked with gelatin post-coating solution at room temperature for $2 \mathrm{~h}$. The antigen-coated wells 


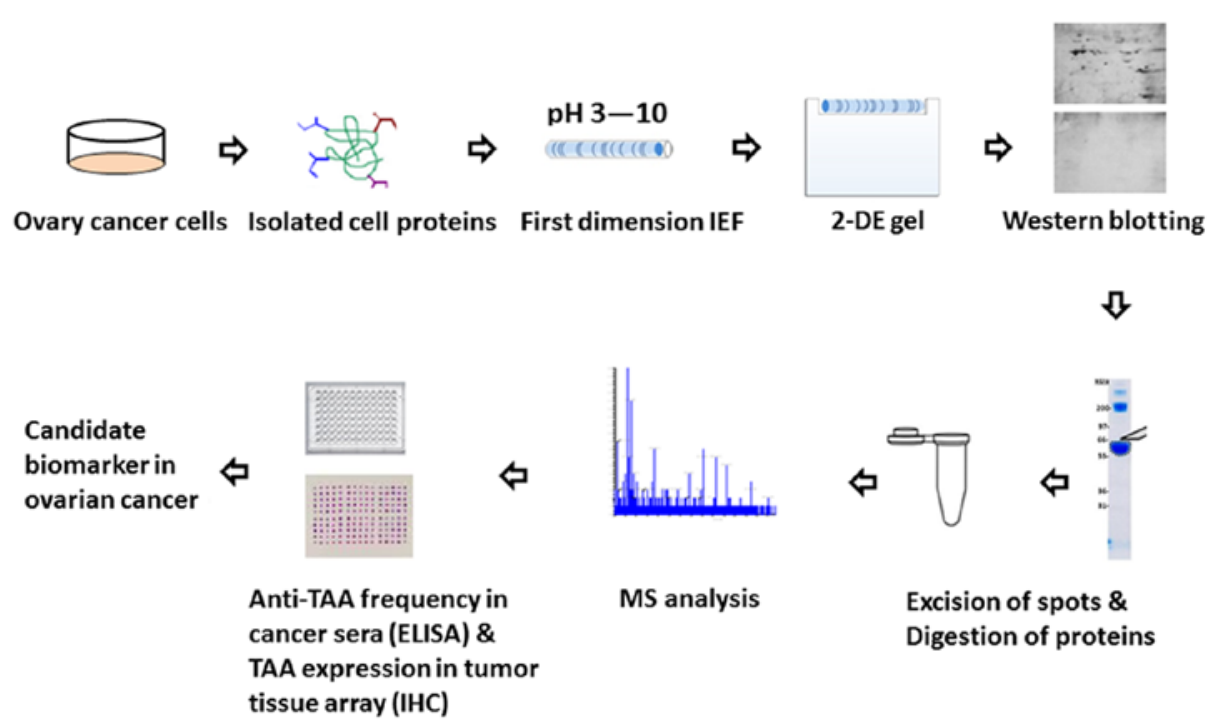

Figure 1. Schematic representation of tumor-associated biomarker identification in ovarian cancer. Concisely, cell extracts of cultured human ovarian cancer cells were used for isoelectrofocusing gel (the first dimension gel) analysis, and then were transferred to SDS-PAGE gel (the second dimension gel). The cellular proteins were subsequently transferred to nitrocellulose membranes or visualized by Coomassie brilliant blue staining. Following immunoblotting of ovarian cancer sera and normal individual sera, several protein spots of interest were excised from the 2-DE gel, digested with trypsin, and subsequently analyzed by liquid chromatography-tandem mass spectrometry (LC-MS/MS). In subsequent studies, we will characterize the identified proteins that are valuable biomarkers in ovarian cancer.

were subsequently incubated with human sera diluted at 1:100 with serum diluent for $2 \mathrm{~h}$ at room temperature. The goat anti-human IgG-HRP and the substrate 2,2'-azino-bis-3-ethylbenzo-thiazoline-6-sulfonic acid (ABTS) (both from Invitrogen, Grand Island, NY, USA) were applied as detection reagents. The average optical density (OD) value was assessed at a wavelength of $405 \mathrm{~nm}$ for data analysis. The cut-off value designating a positive reaction was the mean OD of 45 normal human sera (NHS) added to 3 standard deviations (SDs).

Indirect immunofluorescence (IIF) assay. Hep-2 cell slides (MBL International Corporation, Woburn, MA, USA) were applied to identify the autoantibodies in cancer sera. Polyclonal anti-HSP70 antibody (Sigma-Aldrich) (1:50 dilution) and human sera (1:80 dilution) were incubated at room temperature for $1 \mathrm{~h}$. FITC-conjugated goat anti-human IgG with a 1:200 dilution, and anti-mouse IgG Fab2 Alexa Fluor with a 1:100 dilution were employed as the secondary antibodies, respectively. IIF images were obtained with a laser scanning confocal microscope (LSM 700; Zeiss, New York, NY, USA), using a 20X objective and processed by ZEN 2009 software (Zeiss, Dublin, CA, USA).

Immunohistochemistry (IHC) with tissue array slides. Ovarian cancer tissue array slides with normal controls are commercially available (US Biomax, Inc., Rockville, MD, USA), and were applied to detect the expression of the HSP70 protein. The slides were deparaffinized with xylene and dehydrated with ethanol of different strengths. Antigen retrieval was performed using microwave-heating methods and Trilog $\mathrm{y}^{\mathrm{TM}}$ pretreatment solution for $20 \mathrm{~min}$ at $100^{\circ} \mathrm{C}$ and then the slides were cooled down at room temperature for $50 \mathrm{~min}$. Avidin and biotin block solutions were employed to block nonspecific binding of antibodies for $10 \mathrm{~min}$. The slides were incubated with polyclonal anti-HSP70 antibody (1:50 dilution) overnight at $4^{\circ} \mathrm{C}$. An HRP detection system and a DAB substrate kit were applied as detecting reagents. After counterstaining with hematoxylin, the slides were dehydrated and mounted. Eventually, the sections were observed using a microscope (DM1000; Leica, Heidelberg, Germany).

Statistical analysis. Statistical analysis was performed using SPSS 21.0 software. Data were analyzed using a $\chi^{2}$ test and expressed as the mean \pm 3 SD of OD values with normal controls as determined by ELISA. The results were considered to represent a statistically significant difference when P-values were $<0.01$.

\section{Results}

Identification of immunoreactive proteins in ovarian cancer by $L C$-MS/MS. As indicated in Fig. 1, a proteome-based approach was employed to identify valuable TAAs as biomarkers in ovarian cancer. Concisely, proteins extracted from SKOV3 cells were separated by 2-DE and later transferred onto NC membranes. The pool of sera from 10 patients with ovarian cancer was immunoscreened by western blot analysis. The pool of 10 normal human sera was applied as the control. The results obtained revealed a number of protein spots which were visible on the NC membranes. By comparing and matching protein spots on both membranes with the equivalent protein spots on the 2-DE gels (Fig. 2A), 14 immunoreactive spots were detected with the sera from patients with ovarian cancer (Fig. 2C), but not with the sera from the normal controls (Fig. 2B). In the subsequent study, 14 immunoreactive protein spots were excised from the SDS-PAGE gels, digested with trypsin and further analyzed by LC-MS/MS. The resulting MS/MS spectra were identified using the UniProt protein database, which is a comprehensive database for human protein sequences. As described 


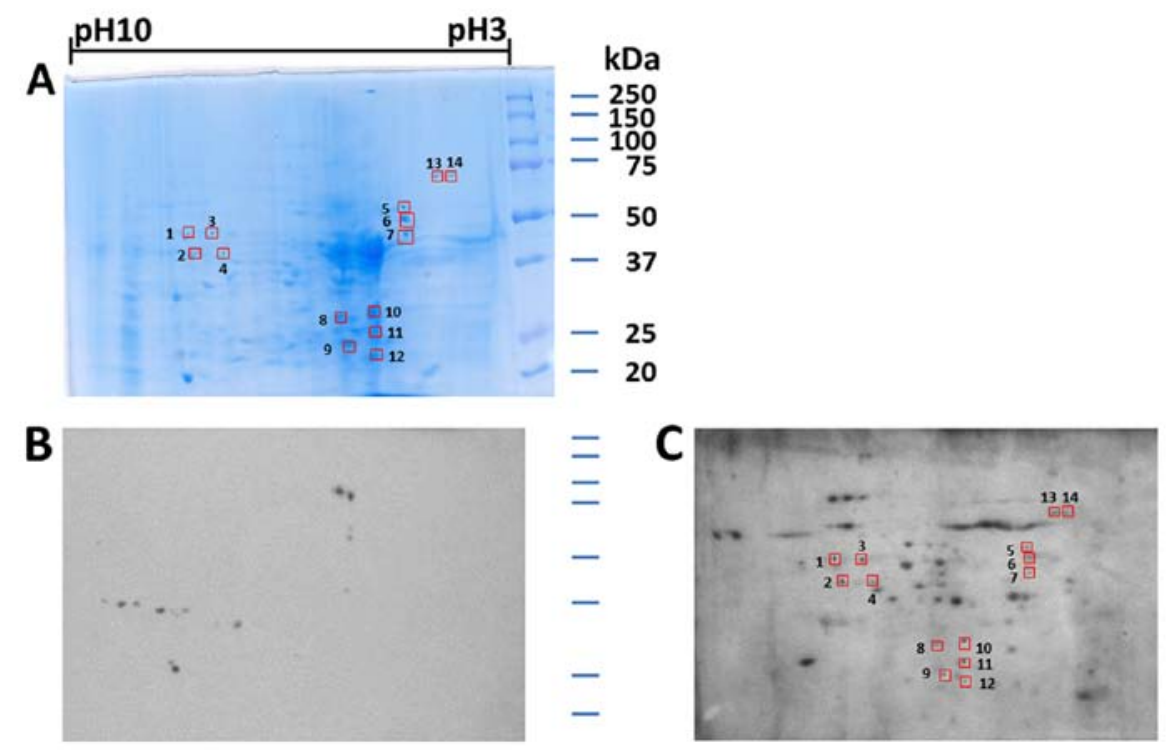

Figure 2. Identification of ovarian cancer-associated proteins by immunoproteomics. (A) Two-dimensional polyacrylamide gel electrophoresis (2-DE) protein profile of SKOV3 cells. (B) The proteins extracted from the SKOV3 cells were separated by 2-DE and transferred onto nitrocellulose membranes for immunoblotting analysis. The pool of normal human sera $(\mathrm{n}=10)$ was applied as the control. (C) Immunoreactive spots from 10 representative ovarian cancer sera were obtained.

Table I. Summary of the identified protein spots by mass spectrometry.

\begin{tabular}{|c|c|c|c|c|}
\hline $\begin{array}{l}\text { Spot } \\
\text { no. }\end{array}$ & $\begin{array}{c}\text { Accession } \\
\text { no. }\end{array}$ & Identified proteins & $\begin{array}{l}\text { Molecular mass } \\
\quad(\mathrm{kDa})\end{array}$ & Protein functions \\
\hline 1 & P06733 & $\alpha$-enolase & 47.1 & Glycolytic enzyme expressed in most human tissues \\
\hline 2 & P06733 & $\alpha$-enolase & 47.1 & Glycolytic enzyme expressed in most human tissues \\
\hline 3 & P06733 & $\alpha$-enolase & 47.1 & Glycolytic enzyme expressed in most human tissues \\
\hline 4 & P06733 & $\alpha$-enolase & 47.1 & Glycolytic enzyme expressed in most human tissues \\
\hline 5 & Q53G71 & Calreticulin variant & 46.9 & $\begin{array}{l}\text { Calcium-binding chaperone that promotes } \\
\text { folding, oligomeric assembly and quality control } \\
\text { in the endoplasmic reticulum }\end{array}$ \\
\hline 6 & Q53G71 & Calreticulin variant & 46.9 & $\begin{array}{l}\text { Calcium-binding chaperone that promotes } \\
\text { folding, oligomeric assembly and quality control } \\
\text { in the endoplasmic reticulum }\end{array}$ \\
\hline 7 & Q53G71 & Calreticulin variant & 46.9 & $\begin{array}{l}\text { Calcium-binding chaperone that promotes } \\
\text { folding, oligomeric assembly and quality control } \\
\text { in the endoplasmic reticulum }\end{array}$ \\
\hline 8 & H7C469 & Uncharacterized protein & 40.4 & \\
\hline 9 & P04083 & Annexin A1 & 38.7 & $\begin{array}{l}\text { Calcium/phospholipid-binding protein which promotes } \\
\text { membrane fusion and is involved in exocytosis } \\
\text { This protein regulates phospholipase A2 activity }\end{array}$ \\
\hline 10 & Q5VU66 & Tropomyosin 3 & 32 & $\begin{array}{l}\text { Binds to actin filaments in muscle and non-muscle cells } \\
\text { Plays a central role, in association with the troponin complex, } \\
\text { in the calcium dependent regulation of vertebrate } \\
\text { striated muscle contraction }\end{array}$ \\
\hline 11 & Q5HY57 & Emerin & 24.9 & $\begin{array}{l}\text { Stabilizes and promotes the formation of a nuclear actin } \\
\text { cortical network. Inhibits } \beta \text {-catenin activity by preventing } \\
\text { its accumulation in the nucleus }\end{array}$ \\
\hline 12 & O43399 & Tumor protein D54 & 22.2 & A marker for breast cancer and acute lymphoblastic leukemia \\
\hline 13 & P08107 & Heat shock $70 \mathrm{kDa}$ protein & 70 & $\begin{array}{l}\text { A chaperone, that binds to nascent polypeptides to facilitate } \\
\text { correct folding }\end{array}$ \\
\hline 14 & P08107 & Heat shock $70 \mathrm{kDa}$ protein & 70 & $\begin{array}{l}\text { A chaperone, that binds to nascent polypeptides to facilitate } \\
\text { correct folding }\end{array}$ \\
\hline
\end{tabular}


Table II. Frequency of the autoantibody against HSP70 in human sera by ELISA.

\begin{tabular}{lcc}
\hline Type of serum & No. tested & $\begin{array}{c}\text { Autoantibody to } \\
\text { HSP70 } \\
\mathrm{n}(\%)\end{array}$ \\
\hline Ovarian cancer & 120 & $26(21.7)^{\mathrm{a}}$ \\
NHS & 85 & $2(2.35)$ \\
\hline
\end{tabular}

Cut-off value, mean \pm 3 SD of NHS; P-value relative to NHS; ${ }^{\mathrm{a} P}<0.01$. NHS, normal human serum.

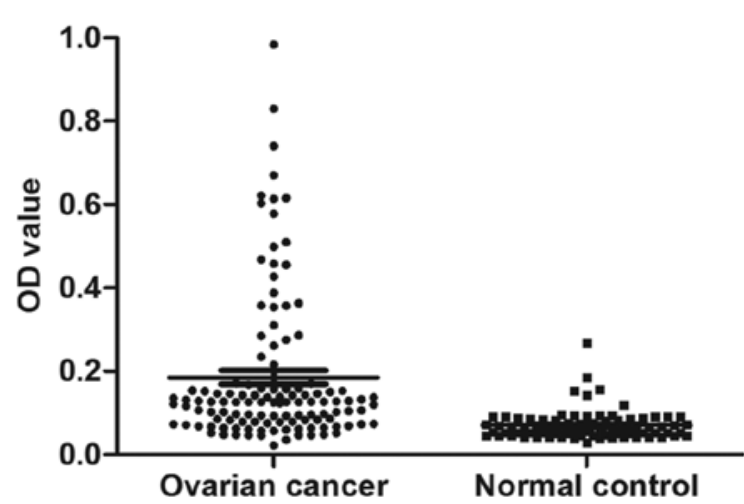

Figure 3. Titers of autoantibody against HSP70 in human sera as determined by ELISA method. The range of titers of anti-HSP70 autoantibody is expressed as the optical density (OD) value obtained from ELISA. The mean $\pm 3 \mathrm{SD}$ of normal human serum (NHS) is shown in relationship to all serum samples. Titers of anti-HSP70 autoantibody in ovarian cancer are much higher than those in the NHS $(\mathrm{P}<0.01)$.

in Table I, 13 of the 14 protein spots were identified by LC-MS/MS. Despite repeated efforts, we could not identify one spot (spot\# 8).

Prevalence of autoantibody against HSP70 in ovarian cancer. The serum level of anti-HSP70 autoantibody was evaluated by ELISA as described in Materials and methods. All in all, 120 sera from patients with ovarian cancer and 85 sera from normal human individuals were available in the present study. As demonstrated in Table II, the prevalence of the anti-HSP70 antibody was $21.7 \%(26 / 120)$ in ovarian cancer, which was significantly higher than that in the NHS group $(2.35 \%, 2 / 85)$ $(\mathrm{P}<0.01)$. Titers of autoantibody against HSP70 in human sera are displayed in Fig. 3. The average titer of the anti-HSP70 antibody in ovarian cancer sera was higher than that in the NHS group $(\mathrm{P}<0.01)$.

IIF staining pattern of HSP7O in Hep-2 cells. To further ascertain the reactivity of the anti-HSP70 antibody in ovarian cancer sera and the intracellular localization of HSP70, Hep-2 cell slides were employed in an indirect IIF assay to detect positive anti-HSP70-ovarian cancer sera using ELISA. As described in Fig. 4, a representative ovarian cancer serum sample positive for the anti-HSP70 antibody as determined by

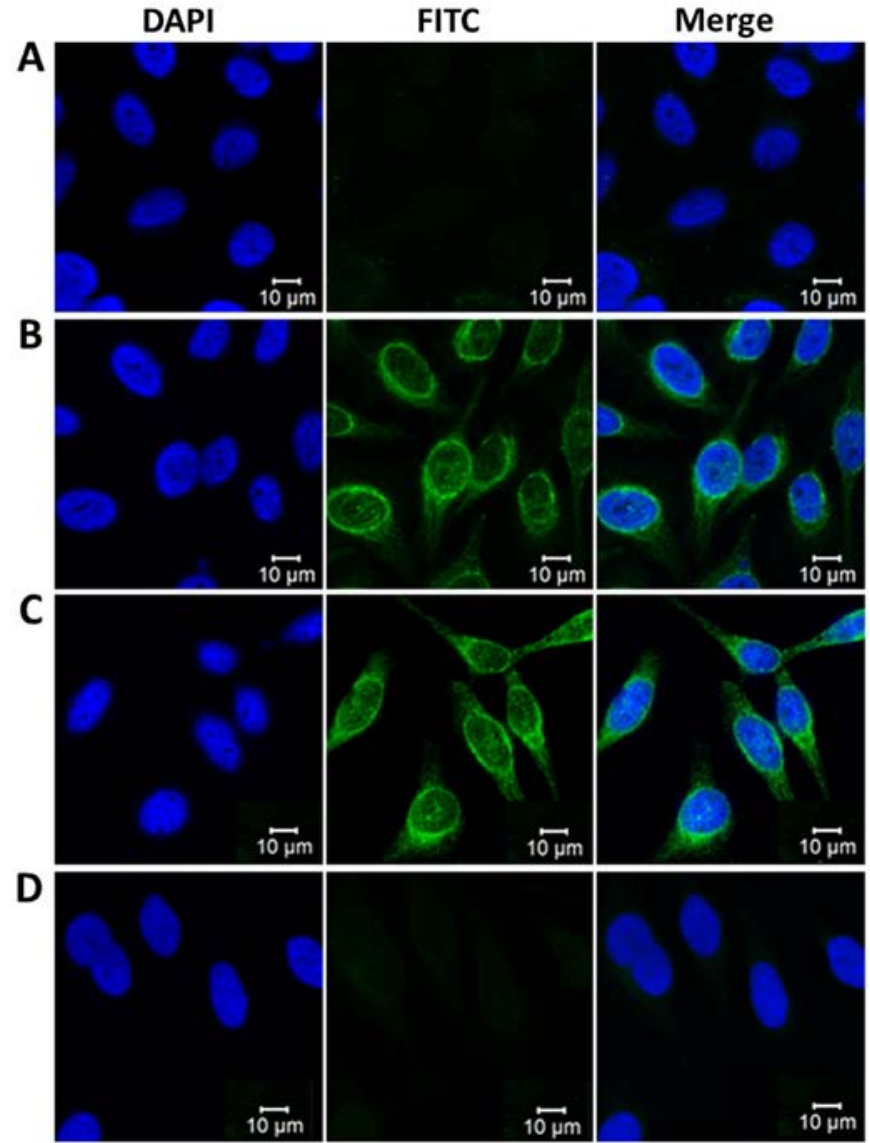

Figure 4. Representative immunofluorescence staining patterns of anti-HSP70 autoantibody-positive ovarian cancer serum. (A) A normal human serum (NHS) served as the negative control. (B) Polyclonal anti-HSP70 antibody that demonstrated a cytoplasmic immunofluorescence staining pattern was applied as a positive control. (C) A representative anti-HSP70 autoantibody-positive ovarian cancer serum sample showed a cytoplasmic immunofluorescence staining pattern. (D) The same ovarian cancer serum sample that was used in panel C was post-absorbed with recombinant HSP70 protein. The fluorescent signal was greatly decreased.
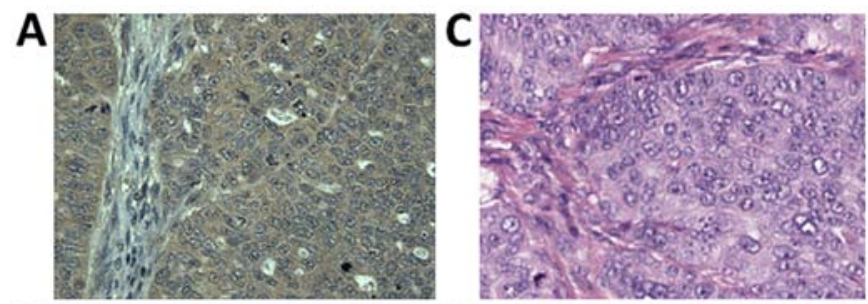

B
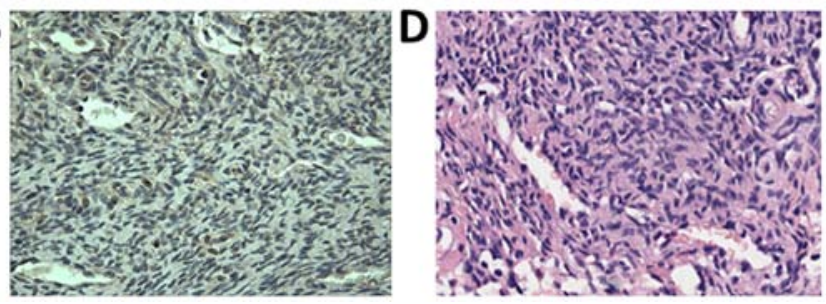

Figure 5. Expression of HSP70 in ovarian cancer and adjacent normal ovarian tissues as determined by immunohistochemistry. The polyclonal HSP70 antibody was used as a primary antibody to detect the expression of HSP70 in ovarian cancer and adjacent normal ovarian tissues. (A) An ovarian cancer tissue with positive staining (magnification, $x 400$ ). (B) An adjacent normal ovarian tissue with negative staining. (C) Ovarian cancer tissue with H\&E staining. (D) Adjacent normal ovarian tissue with H\&E staining. 
Table III. Expression of HSP70 in ovarian cancer tissues and normal controls.

\begin{tabular}{lcc}
\hline Type of tissues & No. tested & $\begin{array}{c}\text { HSP70 positive } \\
\mathrm{n}(\%)\end{array}$ \\
\hline Ovarian cancer & 52 & $49(94.2)^{\mathrm{a}}$ \\
Normal controls & 20 & $3(15)$ \\
\hline
\end{tabular}

P-value of ovarian cancer tissues to normal controls, ${ }^{\text {a }}<0.01$.

ELISA had an intense cytoplasmic staining pattern, which was analogous to the staining pattern obtained by the polyclonal anti-HSP70 antibody which is largely located in the cytoplasm. The fluorescent cytoplasmic staining was significantly attenuated when the same ovarian cancer serum sample was pre-absorbed with recombinant HSP70 protein.

Expression of HSP70 in ovarian cancer and adjacent normal breast tissues by IHC. To further substantiate the representative protein as a biomarker in ovarian cancer, it is important to recognize its expression in ovarian cancer tissue specimens by IHC. In the present study, the expression of HSP70 in ovarian cancer and adjacent normal ovarian tissues were detected by IHC with tissue array slides. Tissue array slides involving 52 breast cancer tissue specimens and 20 adjacent normal breast tissue specimens were purchased for the present study. The polyclonal anti-HSP70 antibody was applied to immunostain the tissue specimens. As displayed in Table III, 49 of the 52 ovarian cancer tissues were positively stained (94.2\%), while 3 of the 20 adjacent normal breast tissues were positively stained (15\%). We concluded that HSP70 was significantly overexpressed in ovarian cancer tissues when compared with the normal control $(\mathrm{P}<0.01)$. The expression of HSP70 in ovarian cancer and in the normal controls is demonstrated in Fig. 5.

\section{Discussion}

Proteomics became feasible with the advancement in two-dimensional polyacrylamide gel electrophoresis (2-DE) (for protein separation with high reproducibility and resolution), and in mass spectrometry (MS) (for protein identification). Although, various techniques have been developed for protein expression analysis (13-15), the conjunction of 2-DE and MS is presently the most extensively used (16-19). In 2001, Brichory et al proposed a proteomic-based method to identify tumor antigens and related autoantibodies in cancers (20). To date, this approach has reported several novel autoantibodies in various malignancies. Autoantibodies against triosephosphate isomerase, superoxide dismutase, Annexin I and II and PGP 9.5 have been revealed as valuable markers in lung cancer $(20,21)$. Autoantibodies against heat-shock protein 70 (HSP70), eukaryotic translation elongation factor 2 (eEF2), peroxiredoxin, heterogeneous nuclear ribonucleoprotein A2 (hnRNP A2), apoptosis-inducing factor (AIE), triosephosphate isomerase (TIM) and prostatic binding protein are more prevalent in patients with hepato- cellular carcinoma (HCC) $(22,23)$. Similarly, autoantibodies against HSP70 and peroxiredoxin VI have been reported as potential diagnostic biomarkers in esophageal squamous cell carcinoma $(24,25)$. Our previous studies employed an immunoproteomic approach to widely screen sera from patients with certain types of cancer including esophageal squamous cell carcinoma (ESCC) and HCC, and sera from patients with precancerous diseases such as liver fibrosis to characterize and identify the potential tumor-associated antigens (TAAs) $(12,26,27)$. In the present study, a total of 14 protein spots were visualized on 2-DE gels and 7 proteins were finally identified by LC-MS/MS.

The cellular and molecular roles of the identified proteins were recorded in the study. A majority of these proteins were reported to be associated with cell proliferation, cell migration, cell invasion and signaling transduction. In order to explore the types of cancer related to these identified proteins, literature searches were performed using PubMed (http:// www.ncbi.nlm.nih.gov/pubmed/). $\alpha$-enolase, a glycolytic enzyme, could be a novel pancreatic ductal adenocarcinoma (PDA)-related antigen (28). Calreticulin has been related to the proliferation and migration of tumor cells and is associated with a poor prognosis for breast, gastric and esophageal cancer patients (29-31). Annexin A1, is an intracellular protein that is aberrantly expressed in various types of cancer, involving breast $(32,33)$, gastric (34-36) and esophageal cancer $(37,38)$. Dysregulation of Annexin A1 is associated with the occurrence of metastasis, invasion and drug resistance of cancers (39). It has been documented that tropomyosin 3 could play a vital role in hepatocarcinogenesis and serve as an important serological biomarker in the early detection of ovarian cancer $(40,41)$. Emerin, as a member of the nuclear lamina-related family, may play a certain role in papillary thyroid carcinoma (42). The tumor protein D54 gene was first identified in human breast cancer (43), and then it was established that it is overexpressed in prostate and ovarian carcinomas (44-47). Several studies have reported that HSP70 is frequently overexpressed in tumor cells, where it has anti-apoptotic functions and acts as a survival protein (48). In the present study, we mainly concentrated on the representative protein HSP70 to evaluate whether this protein can serve as a potential TAA biomarker in the immunodiagnosis of ovarian cancer. As demonstrated above, other identified proteins, including $\alpha$-enolase, calreticulin, Annexin A1, tropomyosin 3, emerin and tumor protein D54 associated with cancer, may be further explored to detect whether they are useful TAAs in ovarian cancer.

To date, various studies have been carried out to detect the autoantibody against HSP70 in various types of cancer such as liver, esophageal, head and neck cancer, as well as nasopharyngeal cancer $(12,25,48,49)$. The present study showed that the frequency of the autoantibody against HSP70 in sera from patients with ovarian cancer was $21.7 \%$ and confirmed that the levels of serum HSP70 autoantibody were significantly higher in ovarian cancer patients than in healthy individuals. The results support the possibility that the autoantibody against HSP70 may be useful as a novel diagnostic marker for detecting ovarian cancer.

Heat shock proteins are known to be overexpressed in a variety of cancers, with HSP70 being the most studied among the family (50). The human HSP70 family consists of at least 8 
highly homologous members that differ from each other in their intracellular expression and localization patterns (51). Among them, the major stress-inducible HSP70 has an important role in cell survival under stressful conditions. HSP70 is usually overexpressed in different cancer cells and is presumed to contribute to the development of tumors $(52,53)$. The expression level of HSP70 is found to be a diagnostic yardstick in several types of cancers, since HSP70 overexpression may be correlated with cancerous cell proliferation (54), increased clinical stage $(55,56)$ and shorter overall survival $(57)$. HSP70 could be a useful tumor marker to identify patients with HCC and earlystage prostate cancer $(58,59)$. A high expression level of HSP70 has been correlated with poor prognosis in breast cancer, acute myeloid leukemia, rectum and endometrial cancer (60-64).

Our results demonstrated that the significant high expression of HSP70 in ovarian cancer tissues may be one of the reasons why HSP70 induced strong autoantibody response in ovarian cancer sera compared to normal individuals. Whether HSP70 can serve as a diagnostic biomarker in ovarian cancer detection, and the mechanisms of how it can cause humoral immune responses in ovarian cancer patients remain to be further explored.

The detection of this humoral response may be helpful not only as a molecular biomarker for immunodiagnosis, but also to guide effective immunotherapies in malignancies. Further investigation is needed to evaluate the sensitivity and specificity of the autoantibody against HSP70 in substantial validation studies and to consider the mechanisms underlying the function of immune responses against HSP70 in ovarian cancer. With regards to the detection of novel autoantibodies, the proteomic-based approach that we used in the present study is a powerful device helping to identify biomarker proteins which may be of clinical use in the future.

\section{Acknowledgements}

The present study was supported by grants from the National Natural Science Foundation of China (81172086), the Project for Tackling Key problems in Science and Technology of Henan Province (1621024100 44), Zhongyuan Scholars Program of Henan Province (162101510006), the Major Project of Science and Technology in Henan Province (161100311400) and the Key Scientific Research Projects of Henan Province (16A330007).

\section{References}

1. Ferlay J, Shin HR, Bray F, Forman D, Mathers C and Parkin DM: Estimates of worldwide burden of cancer in 2008: GLOBOCAN 2008. Int J Cancer 127: 2893-2917, 2010.

2. Siegel R, Ma J, Zou Z and Jemal A: Cancer statistics, 2014. CA Cancer J Clin 64: 9-29, 2014.

3. Siegel R, Naishadham D and Jemal A: Cancer statistics, 2012. CA Cancer J Clin 62: 10-29, 2012.

4. Jayson GC, Kohn EC, Kitchener HC and Ledermann JA: Ovarian cancer. Lancet 384: 1376-1388, 2014.

5. Barua A, Bradaric MJ, Kebede T, Espionosa S, Edassery SL, Bitterman P, Rotmensch J and Luborsky JL: Anti-tumor and anti-ovarian autoantibodies in women with ovarian cancer. Am J Reprod Immunol 57: 243-249, 2007.

6. Naora H, Montz FJ, Chai CY and Roden RB: Aberrant expression of homeobox gene HOXA7 is associated with müllerian-like differentiation of epithelial ovarian tumors and the generation of a specific autologous antibody response. Proc Natl Acad Sci USA 98: 15209-15214, 2001.
7. Karabudak AA, Hafner J, Shetty V, Chen S, Secord AA, Morse MA and Philip R: Autoantibody biomarkers identified by proteomics methods distinguish ovarian cancer from non-ovarian cancer with various CA-125 levels. J Cancer Res Clin Oncol 139: 1757-1770, 2013.

8. Gagnon A, Kim JH, Schorge JO, Ye B, Liu B, Hasselblatt K, Welch WR, Bandera CA and Mok SC: Use of a combination of approaches to identify and validate relevant tumor-associated antigens and their corresponding autoantibodies in ovarian cancer patients. Clin Cancer Res 14: 764-771, 2008.

9. Santucci L, Bruschi M, Ghiggeri GM and Candiano G: The latest advancements in proteomic two-dimensional gel electrophoresis analysis applied to biological samples. Methods Mol Biol 1243: 103-125, 2015.

10. Lee JM and Kohn EC: Proteomics as a guiding tool for more effective personalized therapy. Ann Oncol 21 (Suppl 7): vii205-vii210, 2010.

11. Hays JL, Kim G, Giuroiu I and Kohn EC: Proteomics and ovarian cancer: Integrating proteomics information into clinical care. J Proteomics 73: 1864-1872, 2010.

12. Looi KS, Nakayasu ES, Diaz RA, Tan EM, Almeida IC and Zhang JY: Using proteomic approach to identify tumorassociated antigens as markers in hepatocellular carcinoma. J Proteome Res 7: 4004-4012, 2008.

13. Opiteck GJ, Ramirez SM, Jorgenson JW and Moseley MA III: Comprehensive two-dimensional high-performance liquid chromatography for the isolation of overexpressed proteins and proteome mapping. Anal Biochem 258: 349-361, 1998.

14. Davidsson P, Westman A, Puchades M, Nilsson CL and Blennow K: Characterization of proteins from human cerebrospinal fluid by a combination of preparative two-dimensional liquid-phase electrophoresis and matrix-assisted laser desorption/ionization time-of-flight mass spectrometry. Anal Chem 71: 642-647, 1999.

15. Tragas C and Pawliszyn J: On-line coupling of high performance gel filtration chromatography with imaged capillary isoelectric focusing using a membrane interface. Electrophoresis 21: 227-237, 2000.

16. Tsugita A, Kawakami T, Uchida T, Sakai T, Kamo M, Matsui T, Watanabe Y, Morimasa T, Hosokawa K and Toda T: Proteome analysis of mouse brain: Two-dimensional electrophoresis profiles of tissue proteins during the course of aging. Electrophoresis 21: 1853-1871, 2000.

17. Langen H, Takács B, Evers S, Berndt P, Lahm HW, Wipf B, Gray $C$ and Fountoulakis M: Two-dimensional map of the proteome of Haemophilus influenzae. Electrophoresis 21: 411-429, 2000.

18. Colvis CM, Duglas-Tabor Y, Werth KB, Vieira NE, Kowalak JA, Janjani A, Yergey AL and Garland DL: Tracking pathology with proteomics: Identification of in vivo degradation products of alphaB-crystallin. Electrophoresis 21: 2219-2227, 2000.

19. Jung E, Heller M, Sanchez JC and Hochstrasser DF: Proteomics meets cell biology: The establishment of subcellular proteomes. Electrophoresis 21: 3369-3377, 2000.

20. Brichory FM, Misek DE, Yim AM, Krause MC, Giordano TJ, Beer DG and Hanash SM: An immune response manifested by the common occurrence of annexins I and II autoantibodies and high circulating levels of IL-6 in lung cancer. Proc Natl Acad Sci USA 98: 9824-9829, 2001.

21. Brichory F, Beer D, Le Naour F, Giordano T and Hanash S: Proteomics-based identification of protein gene product 9.5 as a tumor antigen that induces a humoral immune response in lung cancer. Cancer Res 61: 7908-7912, 2001.

22. Takashima M, Kuramitsu Y, Yokoyama Y, Iizuka N, Harada T, Fujimoto M, Sakaida I, Okita K, Oka M and Nakamura K: Proteomic analysis of autoantibodies in patients with hepatocellular carcinoma. Proteomics 6: 3894-3900, 2006.

23. Li L, Chen SH, Yu CH, Li YM and Wang SQ: Identification of hepatocellular-carcinoma-associated antigens and autoantibodies by serological proteome analysis combined with protein microarray. J Proteome Res 7: 611-620, 2008.

24. Fujita Y, Nakanishi T, Hiramatsu M, Mabuchi H, Miyamoto Y, Miyamoto A, Shimizu A and Tanigawa N: Proteomics-based approach identifying autoantibody against peroxiredoxin VI as a novel serum marker in esophageal squamous cell carcinoma. Clin Cancer Res 12: 6415-6420, 2006.

25. Fujita Y, Nakanishi T, Miyamoto Y, Hiramatsu M, Mabuchi H, Miyamoto A, Shimizu A, Takubo T and Tanigawa N: Proteomicsbased identification of autoantibody against heat shock protein 70 as a diagnostic marker in esophageal squamous cell carcinoma. Cancer Lett 263: 280-290, 2008. 
26. Zhang J, Wang K, Zhang J, Liu SS, Dai L and Zhang JY: Using proteomic approach to identify tumor-associated proteins as biomarkers in human esophageal squamous cell carcinoma. J Proteome Res 10: 2863-2872, 2011.

27. Peng B, Huang X, Nakayasu ES, Petersen JR, Qiu S, Almeida IC and Zhang JY: Using immunoproteomics to identify alphaenolase as an autoantigen in liver fibrosis. J Proteome Res 12: 1789-1796, 2013

28. Cappello P, Tomaino B, Chiarle R, Ceruti P, Novarino A, Castagnoli C, Migliorini P, Perconti G, Giallongo A, Milella M, et al: An integrated humoral and cellular response is elicited in pancreatic cancer by alpha-enolase, a novel pancreatic ducta adenocarcinoma-associated antigen. Int J Cancer 125: 639-648, 2009.

29. Bini L, Magi B, Marzocchi B, Arcuri F, Tripodi S, Cintorino M, Sanchez JC, Frutiger S, Hughes G, Pallini V, et al: Protein expression profiles in human breast ductal carcinoma and histologically normal tissue. Electrophoresis 18: 2832-2841, 1997.

30. Chen CN, Chang CC, Su TE, Hsu WM, Jeng YM, Ho MC Hsieh FJ, Lee PH, Kuo ML, Lee H, et al: Identification of calreticulin as a prognosis marker and angiogenic regulator in human gastric cancer. Ann Surg Oncol 16: 524-533, 2009.

31. Du XL, Hu H, Lin DC, Xia SH, Shen XM, Zhang Y, Luo ML, Feng YB, Cai Y, Xu X, et al: Proteomic profiling of proteins dysregulted in Chinese esophageal squamous cell carcinoma. J Mol Med 85: 863-875, 2007.

32. Yom CK, Han W, Kim SW, Kim HS, Shin HC, Chang JN, Koo M, Noh DY and Moon BI: Clinical significance of annexin A1 expression in breast cancer. J Breast Cancer 14: 262-268, 2011.

33. Shen D, Nooraie F, Elshimali Y, Lonsberry V, He J, Bose S Chia D, Seligson D, Chang HR and Goodglick L: Decreased expression of annexin A1 is correlated with breast cancer development and progression as determined by a tissue microarray analysis. Hum Pathol 37: 1583-1591, 2006.

34. Cheng TY, Wu MS, Lin JT, Lin MT, Shun CT, Huang HY, Hua KT and Kuo ML: Annexin A1 is associated with gastric cancer survival and promotes gastric cancer cell invasiveness through the formyl peptide receptor/extracellular signal-regulated kinase/integrin beta-1-binding protein 1 pathway. Cancer 118: 5757-5767, 2012

35. Jorge YC, Mataruco MM, Araújo LP, Rossi AF, de Oliveira JG, Valsechi MC, Caetano A, Miyazaki K, Fazzio CS, Thomé JA, et al: Expression of annexin-A1 and galectin-1 anti-inflammatory proteins and mRNA in chronic gastritis and gastric cancer. Mediators Inflamm 2013: 152860, 2013.

36. Yu G, Wang J, Chen Y, Wang X, Pan J, Li Q and Xie K: Tissue microarray analysis reveals strong clinical evidence for a close association between loss of annexin A1 expression and nodal metastasis in gastric cancer. Clin Exp Metastasis 25: 695-702, 2008.

37. Wang KL, Wu TT, Resetkova E, Wang H, Correa AM, Hofstetter WL, Swisher SG, Ajani JA, Rashid A, Hamilton SR, et al: Expression of annexin A1 in esophageal and esophagogastric junction adenocarcinomas: Association with poor outcome. Clin Cancer Res 12: 4598-4604, 2006.

38. Hu N, Flaig MJ, Su H, Shou JZ, Roth MJ, Li WJ, Wang C, Goldstein AM, Li G, Emmert-Buck MR, et al: Comprehensive characterization of annexin I alterations in esophageal squamous cell carcinoma. Clin Cancer Res 10: 6013-6022, 2004.

39. Guo C, Liu S and Sun MZ: Potential role of Anxa1 in cancer Future Oncol 9: 1773-1793, 2013.

40. Lam CY, Yip CW, Poon TC, Cheng CK, Ng EW, Wong NC, Cheung PF, Lai PB, Ng IO, Fan ST, et al: Identification and characterization of tropomyosin 3 associated with granulin-epithelin precursor in human hepatocellular carcinoma. PLoS One 7 e40324, 2012.

41. Tang HY, Beer LA, Tanyi JL, Zhang R, Liu Q and Speicher DW: Protein isoform-specific validation defines multiple chloride intracellular channel and tropomyosin isoforms as serological biomarkers of ovarian cancer. J Proteomics 89: 165-178, 2013.

42. Kinsella MD, Hinrichs B, Cohen C and Siddiqui MT: Highlighting nuclear membrane staining in thyroid neoplasms with emerin: Review and diagnostic utility. Diagn Cytopathol 41 : 497-504, 2013

43. Byrne JA, Tomasetto C, Garnier JM, Rouyer N, Mattei MG, Bellocq JP, Rio MC and Basset P: A screening method to identify genes commonly overexpressed in carcinomas and the identification of a novel complementary DNA sequence. Cancer Res 55: 2896-2903, 1995.
44. Balleine RL, Fejzo MS, Sathasivam P, Basset P, Clarke CL and Byrne JA: The hD52 (TPD52) gene is a candidate target gene for events resulting in increased $8 \mathrm{q} 21$ copy number in human breast carcinoma. Genes Chromosomes Cancer 29: 48-57, 2000.

45. Wang R, Xu J, Saramäki O, Visakorpi T, Sutherland WM, Zhou J, Sen B, Lim SD, Mabjeesh N, Amin M, et al: PrLZ, a novel prostate-specific and androgen-responsive gene of the TPD52 family, amplified in chromosome 8q21.1 and overexpressed in human prostate cancer. Cancer Res 64: 1589-1594, 2004.

46. Rubin MA, Varambally S, Beroukhim R, Tomlins SA, Rhodes DR, Paris PL, Hofer MD, Storz-Schweizer M, Kuefer R, Fletcher JA, et al: Overexpression, amplification, and androgen regulation of TPD52 in prostate cancer. Cancer Res 64: 3814-3822, 2004.

47. Byrne JA, Balleine RL, Schoenberg Fejzo M, Mercieca J, Chiew YE, Livnat Y, St Heaps L, Peters GB, Byth K, Karlan BY, et al: Tumor protein D52 (TPD52) is overexpressed and a gene amplification target in ovarian cancer. Int J Cancer 117: $1049-1054,2005$

48. Shukla S, Pranay A, D'Cruz AK, Chaturvedi P, Kane SV and Zingde SM: Immunoproteomics reveals that cancer of the tongue and the gingivobuccal complex exhibit differential autoantibody response. Cancer Biomark 5: 127-135, 2009.

49. Tong YQ, Zhang ZJ, Liu B, Huang J, Liu H, Liu Y, Guo FJ, Zhou GH, Xie PL, Li YH, et al: Autoantibodies as potential biomarkers for nasopharyngeal carcinoma. Proteomics 8: 3185-3193, 2008

50. Cohen M, Dromard M and Petignat P: Heat shock proteins in ovarian cancer: A potential target for therapy. Gynecol Oncol 119: 164-166, 2010

51. Tavaria M, Gabriele T, Kola I and Anderson RL: A hitchhiker's guide to the human Hsp70 family. Cell Stress Chaperones 1: 23-28, 1996.

52. Jäättelä M: Escaping cell death: Survival proteins in cancer. Exp Cell Res 248: 30-43, 1999.

53. Aghdassi A, Phillips P, Dudeja V, Dhaulakhandi D, Sharif R, Dawra R, Lerch MM and Saluja A: Heat shock protein 70 increases tumorigenicity and inhibits apoptosis in pancreatic adenocarcinoma. Cancer Res 67: 616-625, 2007.

54. Ralhan R and Kaur J: Differential expression of Mr 70,000 heat shock protein in normal, premalignant, and malignant human uterine cervix. Clin Cancer Res 1: 1217-1222, 1995.

55. Lazaris AC, Theodoropoulos GE, Aroni K, Saetta A and Davaris PS: Immunohistochemical expression of C-myc oncogene, heat shock protein 70 and HLA-DR molecules in malignant cutaneous melanoma. Virchows Arch 426: 461-467, 1995.

56. Kaur J, Srivastava A and Ralhan R: Expression of 70-kDa heat shock protein in oral lesions: Marker of biological stress or pathogenicity. Oral Oncol 34: 496-501, 1998.

57. Alexiou D, Karayiannakis AJ, Syrigos KN, Zbar A, Sekara E, Michail P, Rosenberg T and Diamantis T: Clinical significance of serum levels of E-selectin, intercellular adhesion molecule-1, and vascular cell adhesion molecule-1 in gastric cancer patients. Am J Gastroenterol 98: 478-485, 2003.

58. Abe M, Manola JB, Oh WK, Parslow DL, George DJ, Austin CL and Kantoff PW: Plasma levels of heat shock protein 70 in patients with prostate cancer: A potential biomarker for prostate cancer. Clin Prostate Cancer 3: 49-53, 2004.

59. Chuma M, Sakamoto M, Yamazaki K, Ohta T, Ohki M, Asaka M and Hirohashi S: Expression profiling in multistage hepatocarcinogenesis: Identification of HSP70 as a molecular marker of early hepatocellular carcinoma. Hepatology 37: 198-207, 2003.

60. Nanbu K, Konishi I, Mandai M, Kuroda H, Hamid AA, Komatsu T and Mori T: Prognostic significance of heat shock proteins HSP70 and HSP90 in endometrial carcinomas. Cancer Detect Prev 22: 549-555, 1998.

61. Ciocca DR, Clark GM, Tandon AK, Fuqua SA, Welch WJ and McGuire WL: Heat shock protein hsp70 in patients with axillary lymph node-negative breast cancer: Prognostic implications. J Natl Cancer Inst 85: 570-574, 1993.

62. Thanner F, Sütterlin MW, Kapp M, Rieger L, Kristen P, Dietl J, Gassel AM and Müller T: Heat-shock protein 70 as a prognostic marker in node-negative breast cancer. Anticancer Res 23: 1057-1062, 2003.

63. Thomas X, Campos L, Mounier C, Cornillon J, Flandrin P, Le QH, Piselli S and Guyotat D: Expression of heat-shock proteins is associated with major adverse prognostic factors in acute myeloid leukemia. Leuk Res 29: 1049-1058, 2005

64. Sun XF, Zhang H, Carstensen J, Jansson A and Nordenskjöld B: Heat shock protein $72 / 73$ in relation to cytoplasmic p53 expression and prognosis in colorectal adenocarcinomas. Int J Cancer 74: 600-604, 1997. 